\title{
"DOGSBODY" E "GODSBODY" MA SIMBOLOGIA DO "ULISSES"
}

\author{
PAULO VIZIOLI
}

Universidade de São Paulo

O "Ulisses" de James Joyce é, sem dúvida, uma das obras mais complexas da literatura contemporânea. Richard M. Kain(1) afirma que, "como a Divina Comédia, que Dante explicou poder ser lida em quatro planos, o Ulisses pode ser lido no plano clássico (homérico), no medieval (simbólico), no naturalista (tempo e lugar), e no poético (tonal)". Cada plano oferece um interminável campo de interêsse, exigindo a mais cuidadosa análise. Um exame completo do livro teria que abordar todos, - separadamente e em suas relações, o que constitui tarefa quase sôbre-humana. Não é, pois, de estranhar que a maioria dos críticos se limite a cuidar de apenas um de cada vez. E o caso, por exemplo, do famoso estudo de Stuart Gilbert, que não esconde sua preferência pelo plar:o homérico. Neste nosso despretensioso trabalho, trataremos exclusivamente do segundo plano, ou seja, o simbólico.

O livro de Stuart Gilbert, não obstante a ingenuidade e os exageros que o caracterizam, constifui, sem dúvida, uma contribuição formidável para a interpretação do "Ulisses". Entretanto, a ênfase colocada no exame de cada capítulo, isoladamente, dificulta a percepção da unidade intrínseca da obra, ofuscando, ao mesmo tempo, seu sentido geral. De acôrdo com Cleanth Brooks, em cujas observações em aula o presente artigo principalmente se baseia, é sobretudo na análise dos símbolos, associada ao estudo do comportamento das personagens, que iremos encontrar o significado do discutido romance. E o que tentaremos fazer.

1. R.M. Kain, "Fabulous Voyager", p. 37. 
Há no livro três ou quatro símbolos principais e cêrca de três dezenas de símbolos secundários. Entre êstes, podemos mencionar "metempsicose", "paralaxe", "Jogafora" (Throwaway), "tôrre", "Plumtree's Potted Meat", "corpo-de-cão" (dogsbody), "o mar", "Delta de Cassiopéia", "Elias", "Sêlo de Salomão", "chave", "Dança das Horas", e "Remorso de Consciência" (Agenbite of Inwit). Em geral, são símbolos metamórficos e interrelacionados, e, por isso, qualquer um nos pode servir como ponto de partida. Tomemos, por exemplo, "corpo-de-cão", um dos símbolos menores mais significativos.

"Dogsbody" aparece freqüentemente no livrc, sempre com uma conotação de corpos orgânicos em processo de decomposição. Aliás, é com êste sentido que o mesmo símbolo surge em outros romances inglêses contemporâneos, como "Eyeless in Gaza", de Aldous Huxley, e "The Heart of the Matter", de Graham Greene. Sugere, pois, uma existência totalmente situada no mundo da matéria, cujo fim é a desintegração física e a morte completa. Dessa forma, para insinuar que Paddy Dignam desapareceu inteiramente ao morrer, Stephen Dedalus se refere mentalmente a êle como "um pobre corpode-cão". Assim também o imagina no episódio de Circe, onde "Paddy Dignam escuta com visível esfôrço, pensando cauda em pé, oreIhas levantadas"(2). "Ele ergue seu mutilado rosto cinério para a lua e viva lùgubremente"(3).

A idéia de um ser humano se acabar, como se fôsse um animal, persegue Stephen de tal maneira, que se torna para êle uma entidade independente: "Ah, pobre corpo-de-cão. Aqui jaz o pobre corpo do corpo-de-cão"(4). Todos os homens, inclusive Stephen, passam a ser "corpo-de-cão": "Quem escolheu êste rosto para mim? Este corpo-de-cão para livrar de vermes"(5). Se o jovem não se conforma com essa realidade, sente que deve aceitá-la como a verdadeira na tureza humana: é do corpo-de-cão que viemos, para êle devemos voltar. Seu anonimato é nossa mãe e nosso túmulo podendo ser comparado ao "mar", a respeito do qual Buck Mulligan afirma: "Thalatta! Thalatta! E nossa grande e doce mãe"(6). As marés e as ondas do mar (em grego, thalatta), que surgem e desaparecem sem deixar traço, representam a vida do homem no mundo de hoje, uma vez que o progresso científico reduziu sensivelmente suas esperanças de vida após a morte. Eis porque Stephen, ao caminhar pela praia, olha para o mar e repete as palavras de Mulligan ("nossa doce mãe"),

2. cf. "Ulysses", Modern Library, p. 465.

3. cf. "Ulysses", p. 464.

4. cf. "Ulysses", p. 47.

5. ef. "Ulysses", p. 8.

6. cf. "Ulysses", p. 7. 
completando-as com "Oomb, allwombing tomb"(7) e "Omnis caro ad te veniet". O mar indica nosso princípio e nosso fim, o princípio e ○ fim do "corpo-de-cão".

Mas, se o homem moderno chegou a essa visão de si próprio, o mesmo não se verificou em tôdas as idades. Houve épocas em que o homem esposava a crença num universo ordenado hieràrquicamente, com Deus, no alto, a dirigir os anjos. os sêres vivos e os objetos inanimados. A terra era o centro dêsse universo, e o homem, que a habitava, o centro da criação. O homem acreditava então possuir uma alma eterna; jamais se julgaria um "corpo-de-cão", pois se considerava a imagem do Criador, e, por isso, digno de receber a hóstia, o "corpo-de-Deus" (Godsbody). Aliás, tudo o que existia na terra era uma imagem do que existia no céu. A tal respeito, Magalaner e Kain(8) mencionam a citação de Gilbert "de Hermes Trismegistus, o "Hermes três vêzes grande" de Milton, quanto ao sequinte: "O que existe acima é o que existe embaixo, e o que está embaixo é como o que está acima". A estrêla de seis pontas formada por triângulos entrosados, conhecida como Sêlo de Salomão, representa êsse conceito, pois cada triângulo constitui a imagem espelhada do outro. Assim, o homem microcósmico reflete o universo macrocósmico". Nisto se acreditava no passado. Para Joyce, no entanto, o simbolismo contido no Sêlo de Salomão só pode ser hoje aceito com ironia pelo homem, ou seja, êle pode admitir o reflexo da imagem mas, como em todo espêlho, há uma inversão. Tal inversão vem confirmada à página 584 do "Ulysses" (episódio de Circe), onde os condenados dizem "Dog!" (Cão), enquanto os bemaventurados entoam "God!" (Deus). E os condenados, de certa forma, são os homens atuais, os habitantes de um mundo considerado uma espécie de inferno, não só por Joyce, mas também por T.S. Eliot, Ezra Pound, Hart Crane, e muitos outros.

Quando "Godsbody" predominava na consciência humana, o papel da religião como fator de ordem era muito relevante; a ela associava-se a arte, igualmente baseada na emoção. Hoje, porém, a ciência e o racionalismo se impõem, forçando a fé religiosa a um recuo; a arte, que, de acôrdo com Mathew Arnold (aliás, freqüentemente citado no "Ulisses") deveria tomar o lugar da religião, na realidade, se vê desamparada, e, por isso, tão incapaz quanto a ciência de restabelecer a hierarquia no caos espiritual de hoje.

A ineficácia e a separação da ciência e da arte caracterizam, portanto, o desintegrado mundo do "corpo-de-cão", e constituem, sem

7. Trad. livre: "Uumba, tumba de cujo ventre tudo vem". Cf. "Ulysses", p. 48.

8. apud "Joyce: The Man, the Work, the Reputation", p. 159. 
dúvida, os principais temas do "Ulisses". Essses dois extremos são encarnados no livro pelas duas personagens masculinas em evidência, isto é, Leopold Bloom e Stephen Dedalus. O próprio Joyce confirma claramente êsse ponto, no episódio de f́taca:

"Que dois temperamentos representavam individualmente?

O científico. O artístico."(9)

Não obstante o "toque de artista" reconhecível no "velho Bloom" (essas pequenas contradições existem, pois, afinal, Joyce não procu rou criar tipos, mas sêres humanos plausíveis), essas duas persongens frustradas se opõem; "são figuras complementares, e cada uma se apresenta unilateral e desajustada enquanto só"(10).

Como representantes do "princípio masculino", do poder intelectual ativo que dá forma à natureza passiva ("princípio feminino"), fecundando-a, a arte e a ciência, em vez de se unirem harmoniosa. mente (como "pai" e "filho"), são forçados à incomunicabilidade, tornando-se assim impotentes para a realização da tarefa anteriormente atribuída à religião. Tal impotência e tal isolamento encontram representação simbólica no fato de Stephen e Bloom não possuirem a "chave" de suas próprias moradias (o primeiro deixara a chave com Mulligan, o segundo esquecera a sua em casa), e no fato de ambos se vestirem de prêto, em sinal de luto (Stephen perdera a mãe, e Bloom, havia alguns anos, seu único filho do sexo masculino).

Do isolamento de "pai" e "filho" emerge no romance o retrato de uma civilização cindida, que o autor realça por meio de uma série de símbolos paralelos, em parte irônicos, mas sempre eficientes, por dramatizarem a situação. O símbolo principal é o do errante Ulisses (Bloom), afastado da espôsa, Penélope (Molly), e do filho, Telêmaco (Stephen). $O$ anseio de todos pela reunião é enfatizado pelos motivos de Cristo, Hamlet e Shakespeare. Tais motivos aparecem já no início do livro, quando, por exemplo, Haines afirma:

- "Li uma interpretação teológica disso em algum lugar, disse êle perturbado. A idéia do Pai e do Filho. O Filho tentando se harmonizar com o Pai."(11)

Aí está o paralelo com Cristo. Mas as relações do Príncipe Hamlet com o fantasma de seu pai também são importantes, e desde o primeiro capítulo abundam ecos da conhecida tragédia. Em todos êsses exemplos a comunicação entre pai e filho é penosa, mas ne-

9. cf. "Ulysses", p. 667.

10. Harry Levin, "James Joyce: A Critical Introduction", p. 83.

11. cf. "Ulysses", p. 20. 
cessária; o mesmo se verifica na identificação de Bloom com Stephen, da ciência com a arte. Agora, porém, mais do que nunca tal união parece impossivel e, em conseqüência, as duas personagens permanecem infelizes.

Vejamos, em primeiro lugar, o caso de Stephen. O artista é infeliz porque vive numa sociedade não mais dominada pela religião, mas pela ciência, o mundo dos "fenômenos raturais" de Mr. Bloom. Em tal ambiente de lógica e racionalismo não há mais lugar para a sensibilidade e a imaginação, e o resultado é o ostracismo do artista, que se sente desprovido de raízes, um órfão, o filho de uma natureza já sem significado. Eis porque, pensando na mãe, Stephen murmura:

“...tu me deixaste sòzinho para sempre nos escuros caminhos de minha amargura: e com um beijo de cinzas beijaste minha bôca."(12)

Sua mãe, quase abandonada pelo espôso indiferente (no qual alguns críticos surpreendentemente vêem a religião, relacionando seu nome, Simâo, com Pedro e a lgreja), se tornou, ao morrer, um "corpo-decão", um "rosto cinério". Stephen, tendo abandonado a religião com um satânico "Non serviam!"(13), influenciado pelo racionalismo, sentiu-se, conseguintemente, responsável pela desgraça materna, sendo o tempo todo perseguido por tremendo remorso de consciência (a que sempre se refere como "Agenbite of Inwit", nome de antigo livro inglês sôbre o assunto). Êste sentimento, ave no plano naturalista do romance encontra justificativa na recusa do moço de orar pela mãe moribunda, quando esta lhe pediu que o fizesse, se evidencia notadamente à página 240 do "Ulysses", onde aparece combinado com os motivos do mar, do ventre e da tumba, que o devorarão como o fizeram a sua mãe, a quem não logrou salvar:

"Ela está se afogando. Agenbite. Salva-a. Agenbite. Todos contra nós. Ela me afogará consigo, olhos e cabelo. Anéis frouxos de cabelos de ervas marinhas à minha volta, meu coração, minha alma. Morte verde e salgada.

Nós.

Agenbite of Inwit. Inwit's agenbite.

Miséria! Miséria!"

A lembrança de sua mãe à beira da morte é acompanhada pela das palavras latinas então cantadas em sua homenagem: "Liliata rutilan-

12. cf. "Ulysses", p. 387.

13. cf. "Ulysses", p. 567. Ver também o desenvolvimento de Stephen em "A Portrait of the Artist as a Young Man". 
tium te confessorum turma circumdet"(14). O tanger dos sinos, ligado por êle ao mesmo fato, igualmente o tortura. Tamanho é seu senso de culpa, que, no alucinante episódio de Circe, quando a imagem de sua mãe surge à sua frente, suplicando-lhe que se arrependa, Stephen se justifica bradando:

"Dizem que te matei, māe. Ele ofendeu tua memória. O câncer o fêz, não eu. O destino."(15)

Stephen não a matou; fê-lo um "fenômeno" (o câncer), no mundo dos fenômenos da ciência. E é esta que fornece as armas para "usurpadores" como Buck Mulligan, considerado por Hugh Kenner (16) um dialético, interessado apenas em seus jogos de espírito. Mulligan, no primeiro capítulo do livro, ofende profundamente Stephen ao lembrá-lo de que sua mãe está "beastly dead" (bestamente morta), isto é, morta como um animal, um "corpo-de-cão". Sua atitude é idêntica à de Rudolph Virag, avô de Bloom, que, no episódio de Circe, enxovalha o nome da Virgem Maria, o princípio feminino em sua forma ideal, afirmando que "Panthera, o centurião romano, a poluiu com seus genitórios"(17), sendo, portanto, o verdadeiro pai de Cristo. Também êle transforma o "corpo-de-Deus" em "corpo-de. cão".

Em tal meio, o artista, sem o apoio que a religião lhe concedia, se acha debilitado, rejeitado, impotente. Por isso, Stephen não pode voltar ao lar (é um estranho ali), nem pode ficar na tôrre que alugou (esta the foi usurpada):

"Não dormirei aqui. Para casa também não posso ir."(18) Está só em seu mundo, lutando, como Pirro, "por uma causa perdida"(19). Daí sua infelicidade: precisa de um "pai".

Se Bloom representa o temperamento científico, como Joyce afirma, êle deveria se sentir ditoso no mundo dos "fenômenos". De fato, êle é menos infeliz e mais acomodado que Stephen, pois vive em seu elemento. E o herdeiro do "corpo-de-cão". Aliás, quando seu avô, Virag, faleceu, deixou êle a seus cuidados Athos, um cão, dizendo-lhe: "Pobre Athos! Sejas bom para com Athos, Leopold, é meu último desejo"(20). Ao que Bloom respondeu: "Seja feita a tua vontade".

14. cf. "Ulysses", p. 12.

15. cf. "Ulysses", p. 565.

16. of. Hugh Kenner, "Dublin's Joyce", p. 222.

17. of. "Ulysses", p. 510 .

18. ef. "Ulysses", p. 24.

19. cf. "Ulysses", p. 132.

20. cf. "Ulysses", p. 89. 
Para Leopold Bloom o mundo da matéria é a única realidade. O "corpo-de-Deus" é o "corpo-de-cão". Assim, em sua cômica ingenuidade, descreve nestes têrmos, para si mesmo, a santa comu. nhão:

"O sacerdote passou por êles, segurando a coisa nas mãos"(21).

"O quê? Corpus. Corpo. Cadáver"(22)

O "corpo-de-Deus" (a hóstia) se transforma em "coisa" e em "cadáver", bestamente morto. Se "Godsbody" é igual a "dogsbody", a recíproca é também verdadeira, e a eucaristia de Bloom é seu próprio corpo(23), para o qual dedica verdadeiro culto em seu templo, a "mesquita dos banhos".

Em conseqüência disso, êle diverge profundamente de Stephen. Enquanto o "velho Bloom" come "com satisfação os órgãos internos dos animais"(24), - especialmente rins de porco, com seu leve sabor de urina, - Stephen detesta tudo o que lhe possa lembrar a matéria corruptível:

"Hálitos mortos eu vivendo respiro, caminho sôbre o pó morto, devoro os restos urinosos de todos os mortos."(25)

O artista se vê perseguido pelo remorso, e o tanger dos sinos the traz torturantes lembranças; Bloom vive mais despreocupado, e a mensagem dos sinos é alegre e vazia para êle:

"Que ecos daquele som foram por ambos e cada qual ouvidos?

Por Stephen:

Liliata rutilantium. Turma circumdet.

lubilantium te virginum. Chorus excipiat.

Por Bloom:

Heigho, heigho,

Heigho, heigho."(26)

Bloom possui instintos generosos, mas sua preocupação principal é com sua própria vida; sua utopia, amplamente descrita no episódio de Itaca, - capítulo que Joyce considerava "o patinho feio" de "Ulisses", - é a posse de bens materiais.

Apesar de tudo, êle não é feliz. Seu símbolo é Odisseu, o exi-

21. cf. "Ulysses", p. 79.

22. No original: "Corpus. Body. Corpse." - A palavra corpse (cadáver) provém de corpus.

23. cf. "Ulysses", p. 85: "This is my body". "Éste é meu corpo."

24. cf. "Ulysses", p. 55.

25. cf. "Ulysses", p. 51 .

26. cf. "Ulysses", p. 688 . 
lado involuntário, o navegante que tenta o tetôrno ao lar. Bloom, de fato, se encontra só, isolado em sua sociediade, incapaz de con. servar sua própria herança (significativamente, o cāo Athos morreu logo depois de Virag), ou de possuir sua propria mulher, Molly, sempre em busca de novos amantes. Molly Bloom representa Gea-Terra, "cheia de semente", a mãe-natureza, o princípio feminino aguardando a fecundação pelo princípio masculino. Fälta, porém, à ciência imaginação criadora, e suas tentativas de dar forma, de explicar a natureza, resultam em visōes imperfeitas e fragmentárias. A visão total não emerge. Por essa razão, Bloom é retratado como um frustrado sexual. A esterilidade de suas relaçōes matrimoniais não satisfaz Molly, pais, sem produzir frutos, a vida nāo tem sentido. Para possui-la, Bloom necessita devolver o significado à Existência da espôsa: precisa de um "filho".

A tragédia que o livro apresenta, portanto, é a da vida moderna, sem sentido numa natureza amorfa (Molly), elıquanto a arte (Stephen) e a ciência (Bloom) se esforçam inùtilmente por ocupar o lugar deixado vago pelo recuo da religião. Tudo isso desponta claramente dos símbolos principais. Assim, se Bloom e Stephen são, respectiva mente, as versóes atuais de Odisseu e Telêmaco, Hamlet-Pai e o Prncipe Hamlet (e, derivando dêstes, Shakespeare c Hamlet), Deus-Pai e Cristo (trocando, às vêzes, de posição), Molly é a versão de Penélope, Gertrude, Anne Hathaway (espôsa de Shakespeare), e Mario. Ela poderia ser pura como Maria e fiel como Penélope, mas, no mun do moderno, aviltada, se assemelha a Gertrude e a Anne Hathaway (de acôrdo com o caráter desta na absurda, mas hábil teoria de Siephen sóbre a vida de Shakespeare, no episódio de Sila e Caribdis). Em outras palavras, ela poderia ser a mãe e a espôsa de "Goósbc $d y "$ ", porém, seu filho e seu espôso são apenas "dogsbodies". Ela é a vítima "depravationis huius seculi"(27), a mulher poluida pelo centurião romano(28). Como um "corpo-de-cão" se sente vazia, - e in. feliz, porque "a natureza detesta o vácuo"(29). Requer um princípio masculino integrado, um filho e um marido, talvez algo como a fusão de Bloom e Stephen. Eis porque demonstra para com ambos sentimentos ao mesmo tempo eróticos e maternais. Se trai Bloom, também tem ciúmes dêle:

"a senhorita Stack trazendo-Ihe flôres as piores que podia encontrar no fundo da cesta qualquer coisa para poder entrar no

27. cf. "Ulysses", p. 396

28. cf. "Ulysses", p. 510.

29. cf. "Ulysses", p. 162. 
quarto de um homem com sua voz de solteirona tentando imaginar que êle estava morrendo por causa dela"(30).

Slephen, contudo, também é desejado:

"estou cerfa de que será formidável se eu puder ir com um jovem poeta simpático na minha idade'(31).

Concomitantemente, ela desejaria ser a mãe de Dedalus:

"bem é triste que êsses que têm um filho tẽo bom quanto êle não estejam satisfeitos e eu nenhum"(32).

Por outro lado, promete a si mesma dedicar a Bloom as atenções que uma mãe tem por um filho:

"bem êles não vão pegar meu marido outra vez em suas garras se eu puder evitar isso rindo dêle pelis costas"(33).

Como, porém, a desejada ligação entre "pai" e "filho" não oferece esperanças de concretização, o reino do "corpo-de-cão" haverá de prosseguir, ainda que, do ponto de vista espiritual, sua civilização não tenha podido "produzir nada que o mundo julgasse digno de nota"(34). Molly tenta novas soluções (novos amantes), mas por si não pode fazer coisa alguma. Permanece cheia de semente, porém, sua fecundidade é apenas potencial.

De fudo o que foi dito, podemos concluir que o livro retrata, entre outras coisas, a desintegração cultural de nossa época. Não procura, entretanto, apontar uma solução para os problemas atuais. isso porque, de acôrdo com as idéias estéticas de Joyce, expostas em "A Portrait of the Artist as a Young Man", e fundamentadas em Sto. Tomás de Aquino, a literatura deve ser estática, não cinética. A obra de arte nos oferece uma epifania, revela uma situação, sem necessidade de sugerir soluçōes para os problemas levantados. Assim, "Ulisses" é, de certa maneira, uma epifania de "dogsbody", o símbolo que $o$ autor escolheu para nossa civilização.

Nem todos os críticos, entretanto, se conformam com isso, interpretando o encontro de Stephen com Bloom como a consumação da anelada identificação de "filho" e "pai". Mas o encontro de ambos foi assaz fortuito $e$, por isso, os argumentos em favor dessa identi ficação não muito convincentes. O argumento de William York Tin-

30. cf. "Ulysses", p. 723.

31. cf. "Ulysses, p. 761,

32. cf. "Ulysses", p. 763.

33. cf. "Ulysses", p. 759.

34. apud "James Joyce: Two Decades of Criticism", p. 232. 
dall, por exemplo, é que a letra final do livro é s e a inicial também é s, e isto "nos leva num círculo para Stephen novamente, e de volta a Mr. Bloom"(35).

Todavia, se não podemos ver no encontro citado uma identificação, nem por isso deixa o livro de apresentar alguns aspectos otimistas. O principal dêles se encontra no famoso monólogo interior de Molly Bloom, que começa e termina com a palavra sim, significando a afirmação de continuidade da natureza. À idéia de continuidade $O$ autor acrescenta a de recorrência, havendo muitos símbolos e expressões insinuando a possibilidade de retôrno ao mundo de "Godsbody", tais como, a repetição da palavra "metempsicose", as referências a Joaquim Abbas(36), - que, como Vico, desenvolvera uma teoria de desenvolvimento cíclico na história da civilização, - as alusões a Moisés (a Terra da Promissão) e à volta de Elias(37). Até mesmo a "Dança das Horas" da ópera "La Gioconda" de Ponchielli se torna um símbolo de recorrência: "Horas do anoitecer, moças com véus diáfanos cinzentos. Horas noturnas, de prêto, com adagas e máscaras. Idéia poética, rosa, depois ouro, depois cinza, depois negro. E também fiel à vida. O dia, depois a noite"(38).

Aí está, portanto, como, através do estudo parcial do simbolismo do "Ulisses", pudemos interpretar o grande livro. Na verdade, nossa interpretação é incompleta, pois nenhuma referência foi feita aos outros temas da obra, entre os quais o importantíssimo tema nacional irlandês, que aparece, pràticamente, em todos os capítulos. E rambém uma interpretação discutível, como, aliás, tôdas as que apareceram até agora. E, finalmente, como interpretação, deixa de revelar "Ulisses" em tôda a sua complexidade, com a sua admirável estrutura, seu minucioso naturalismo, sua extrąordinária fôrça poética, e seu irresistível humor. Trata-se, como dissemos no início, de um modesto trabalho, que visa sòmente esclarecer o sentido do grande romance, - ou, pelo menos, mostrar sua unidade de concepção, para os leitores brasileiros, cada vez mais interessados na discutida obra de Joyce, especialmente depois que foi dada a lume a excelente tradução de Antonio Houaiss.

35. W.Y. Tindall, "James Joyce", p. 37

36. cf. "Ulysses", p. 40.

37. cf. "Ulysses", pp. 149, 389, 660.

38. cf. "Ulysses", 0. 69. 